\title{
The correlation between colposcopy, cervical cytology and histopathology in the diagnosis and management of cervical lesions: a cross sectional study
}

\author{
Pooja Gupta $^{1}$, Mariyam Faruqi ${ }^{1}$, Subrat Chandra ${ }^{2 *}$, Sameer S. Shah ${ }^{3}$, Rupita Kulshrestha ${ }^{4}$
}

\author{
${ }^{1}$ Department of Obstetrics and Gynecology, Dr. Ram Manohar Lohia Institute of Medical Sciences, Lucknow, Uttar \\ Pradesh, India \\ ${ }^{2}$ Department of Pathology, Dr. Ram Manohar Lohia Institute of Medical Sciences, Lucknow, Uttar Pradesh, India \\ ${ }^{3}$ Consultant Ashvini Maternity Home and Endoscopy Clinic, Mumbai, Maharashtra, India \\ ${ }^{4}$ Department of Obstetrics and Gynecology, Mayo Institute of Medical Sciences, Lucknow, Uttar Pradesh, India
}

Received: 21 May 2020

Accepted: 30 May 2020

*Correspondence:

Dr. Subrat Chandra,

E-mail: drsubratcgupta@gmail.com

Copyright: () the author(s), publisher and licensee Medip Academy. This is an open-access article distributed under the terms of the Creative Commons Attribution Non-Commercial License, which permits unrestricted non-commercial use, distribution, and reproduction in any medium, provided the original work is properly cited.

\begin{abstract}
Background: The study was undertaken to see the correlation between cervical cytology, histopathology and colposcopy in the diagnosis and management of various cervical lesions.

Methods: It is a cross sectional study conducted at a tertiary care hospital in Mumbai, in the department of obstetrics and gynecology from February 2007 to March 2008. A total 55 sexually active women were enrolled for the study who belonged to age group greater than 20 years with history of chronic leucorrhoea or post-coital bleeding/spotting, intermenstrual bleeding/spotting or examination findings of erosion, an unhealthy cervix, a lesion bleeding on touch or an abnormal or suspicious Papanicolaou smear. These women then underwent cytology, colposcopy and cervical biopsy.

Results: The accuracy of cytology when compared to colposcopy was $81.82 \%$. The accuracy of colpo-histopathology was $83.6 \%$. The combined accuracy was $76.36 \%$.

Conclusions: The simultaneous use of cytological studies and screening colposcopy has been shown to increase the cervical cancer detection. Colposcopy offers an excellent tool in the hands of a gynaecologist to evaluate the uterine cervix and it is not possible to develop this kind of perspective by any other method.
\end{abstract}

Keywords: Cervical cancer screening, Colposcopy, Female genital tract malignancy, Histopathology, Pap smear

\section{INTRODUCTION}

Worldwide carcinoma cervix is the second most common cancer among women. ${ }^{1}$ However, in India it leads the list of cancers afflicting the female genital tract, accounting for roughly $80 \%$ of these cases. ${ }^{2}$ It accounts for $7 \%$ of all female malignancies in developed countries as against $24 \%$ in developing countries. ${ }^{3,4}$

The accessibility of the uterine cervix being a relatively smaller organ, the propensity of cells to exfoliate from the pre-cancerous lesions, the evidence from pathological studies of the existence of histological changes from mild atypia's through pre-malignant lesions to frank malignancy, the apparently prolonged natural history of long pre-malignant phase and the ability for being detected cytologically, provide the best potential for control of a cancer by population screening. ${ }^{5}$ One of the major problems in modern gynaecological oncology is the early diagnosis of pre-malignant cervix and not just treatment of progressive cervical cancer. This attitude is justified in sense of ethics (quality of life of the patients 
is better as less radical methods of therapy are being applied), personnel use (a smaller medical team is involved) and financial needs (expensive radical operations, radio and chemotherapy and rehabilitation of patient are avoided). ${ }^{6}$ Similarly, ways to diagnose cervical cancer has been gradually developing and it has been scientifically validated. Some of the tests that are followed worldwide are exfoliative cytology, colposcopy, histological studies, human papilloma virus (HPV) studies and the molecular cytogenetic studies that is still in inception phase.

Hence, authors proposed to study the usefulness of colposcopy and cytology as an adjunct to histopathology in detection of dysplasia and early neoplasia of the uterine cervix.

\section{METHODS}

It is a cross sectional study conducted at a tertiary care Hospital in Mumbai, in the department of obstetrics and gynecology from February 2007 to March 2008.

This study was done with the aim to study the age wise incidence of cervical lesions, the correlation between parity and cervical lesions, to study the symptomatology (distribution of chief complaints) in patients and to study the correlation between cervical cytology, histopathology and colposcopy.

\section{Inclusion criteria}

- All sexually active women

- In the age group greater than 20 years with

- History of chronic leucorrhoea or post-coital bleeding/spotting, intermenstrual bleeding/spotting

- Examination findings of erosion, an unhealthy cervix, a lesion bleeding on touch

- An abnormal or suspicious Papanicolaou smear.

\section{Exclusion criteria}

- Those who refuse to participate in the study

- $\quad$ Sexually inactive females.

Written informed consent was taken from all the 55 women enrolled for the study. After taking proper history and general examination, a per speculum examination was done in these patients to rule out any gross pathology.

In case of leucorrhoea, vaginal smears were done in all cases to rule out infection like candidiasis, trichomonas vaginalis, to detect pseudo mycelia and budding yeast cells and flagellated parasites in trichomonas. Patients were treated for specific and non-specific infection with anti-fungal and anti-protozoal agents. Pap smears were taken in these patients after treating the infections and interpreted as per the Bethesda system of cytologic classification. $^{7,8}$ All the patients whose cytology was done were instructed beforehand not to douche the vagina or have sexual intercourse for at least 3 days before the examination. Pap smears were taken from ectocervix and endocervix by Ayres spatula and cyto-brush. Smear was made on a glass slide and fixed immediately in a bottle containing 95\% absolute alcohol. Most of the women included in the study underwent Pap smear and colposcopic examination at the same sitting. There were the others who were referred with an abnormal Pap smear in whom only colposcopy was done. Unsatisfactory colposcopies underwent endocervical curettage but were excluded in the study group. Colposcopic directed biopsy were taken in all cases. In women with pre-malignant lesions, loop electrosurgical excision procedure (LEEP) was performed.

\section{Statistical analysis}

After completion of study data was statistically described in frequencies (number of cases) and percentages (\%) when appropriate. The relevant data were entered in Microsoft excel software 2013. All the data were exported to the software SPSS version 11.5 and analysis was done. Chi square test was used for comparison of data for statistical significance. For descriptive statistics percentage, mean and standard deviation was calculated.

\section{RESULTS}

This is a cross sectional study where 55 women who gave consent to participate were enrolled in the study.

Table 1: Age-wise distribution.

\begin{tabular}{|c|c|c|c|c|}
\hline \multirow{2}{*}{$\begin{array}{l}\text { Age in } \\
\text { years }\end{array}$} & \multicolumn{2}{|c|}{$\begin{array}{l}\text { Total no. of cases } \\
(n=55)\end{array}$} & \multicolumn{2}{|c|}{$\begin{array}{l}\text { Pre/malignant } \\
\text { cases }(n=10)\end{array}$} \\
\hline & No. & Percentage & No. & Percentage \\
\hline $21-30$ & 6 & $10.91 \%$ & 0 & $0.00 \%$ \\
\hline $31-40$ & 26 & $47.27 \%$ & 6 & $23.08 \%$ \\
\hline $41-50$ & 16 & $29.09 \%$ & 3 & $18.75 \%$ \\
\hline$>50$ & 7 & $12.73 \%$ & 1 & $14.29 \%$ \\
\hline
\end{tabular}

Table 2: Parity.

\begin{tabular}{|lllll|}
\hline \multirow{2}{*}{ Parity } & \multicolumn{2}{l|}{$\begin{array}{l}\text { Total no. of } \\
\text { cases }(\mathbf{n}=55)\end{array}$} & \multicolumn{2}{l|}{$\begin{array}{l}\text { Pre-malignant and } \\
\text { malignant cases }(\mathbf{n}=\mathbf{1 0})\end{array}$} \\
\cline { 2 - 5 } & No. & Percentage & No. & Percentage \\
\hline 0 & 1 & $1.82 \%$ & 0 & $0.00 \%$ \\
\hline 1 & 4 & $7.27 \%$ & 0 & $0.00 \%$ \\
\hline 2 & 16 & $29.09 \%$ & 0 & $0.00 \%$ \\
\hline 3 & 21 & $38.18 \%$ & 5 & $23.81 \%$ \\
\hline 4 & 5 & $9.09 \%$ & 3 & $60.00 \%$ \\
\hline 5 & 3 & $5.45 \%$ & 0 & $0.00 \%$ \\
\hline$>5$ & 5 & $9.09 \%$ & 2 & $40.00 \%$ \\
\hline
\end{tabular}

The majority of study population fell in the range of 3150 years $(76.36 \%)$. Majority of the pre-malignant and malignant cases were seen in the age group of 31-40 years (Table 1). 
This study showed that the occurrence of pre-malignant and malignant lesions increases as parity increases (Table 2 ). The commonest complaint among all the women was in general leucorrhoea $(49.09 \%)$ while intermenstrual bleeding and post-coital bleeding were the commonest complains in pre-malignant and malignant cases (Table 3).

Table 3: Symptoms.

\begin{tabular}{|lllll|}
\hline \multirow{2}{*}{ Symptom } & Total no. of cases $(\mathbf{n = 5 5})$ & Pre/malignant cases $(\mathbf{n = 1 0})$ \\
\cline { 2 - 5 } & No. & Percentage & No. & Percentage \\
\hline Asymptomatic & 13 & $23.64 \%$ & 2 & $15.38 \%$ \\
\hline Post-coital bleeding/spotting & 6 & $10.91 \%$ & 2 & $33.33 \%$ \\
\hline Intermenstrual bleeding/spotting & 6 & $10.91 \%$ & 2 & $66.67 \%$ \\
\hline Leucorrhoea & 27 & $49.09 \%$ & 0 & $7.41 \%$ \\
\hline Something coming out per vaginum & 3 & $5.45 \%$ & $0.00 \%$ \\
\hline
\end{tabular}

Table 4: Clinical impression.

\begin{tabular}{|lllll|}
\hline \multirow{2}{*}{ Clinical impression } & \multicolumn{2}{l}{ Total no. of cases $(\mathbf{n}=\mathbf{5 5})$} & \multicolumn{2}{l|}{ Pre/malignant cases $(\mathbf{n = 1 0})$} \\
\hline Erosion & No. & Percentage & No. & Percentage \\
\hline Unhealthy cervix & 19 & $34.55 \%$ & 2 & $20 \%$ \\
\hline Inflammation & 22 & $40.00 \%$ & 8 & $80 \%$ \\
\hline Decubitus ulcer & 9 & $16.36 \%$ & 0 & $0.00 \%$ \\
\hline Polyp & 3 & $5.45 \%$ & 0 & $0.00 \%$ \\
\hline
\end{tabular}

Table 5: Histopathology.

\begin{tabular}{|llll|}
\hline \multirow{5}{*}{ Normal } & & Total number of cases $(\mathbf{n = 5 5})$ & Percentage \\
\hline \multirow{5}{*}{ Abnormal } & Chronic cervicitis & 0 & $0.00 \%$ \\
\cline { 2 - 4 } & Polyp & 40 & $72.72 \%$ \\
\cline { 2 - 4 } & Parakeratosis & 2 & $3.64 \%$ \\
\cline { 2 - 4 } & CIN - I & 3 & $5.45 \%$ \\
\cline { 2 - 4 } & CIN - II & 02 & $3.64 \%$ \\
\cline { 2 - 4 } & CIN - III & 1 & $1.82 \%$ \\
& CIS & 1 & $3.82 \%$ \\
& Microinvasive carcinoma & 1 & $1.84 \%$ \\
& Invasive carcinoma & 3 & $5.45 \%$ \\
\hline
\end{tabular}

The majority of the patients in the study group had unhealthy cervix as the major clinical finding (40\%). Erosion accounts for $34.55 \%$, while inflammation, decubitus ulcer and polyp collectively account for $25.45 \%$. None of the patients of decubitus ulcer, inflammation, polyp had pre-malignant or malignant lesion of cervix. The percentage of pre-malignancy and malignancy in the given Table 4 was calculated taking the number of pre-malignant and malignant cases in each group from the total number of pre-malignant and malignant cases $(n=10)$. $80 \%$ of the pre-malignant and malignant cases were from the unhealthy cervix group (Table 4). All the cervical biopsies showed some form of abnormality, maximum being inflammatory. Chronic cervicitis was seen in $72.72 \%$ of the cases, while parakeratosis (cases of decubitus ulcer) accounted for
$5.45 \%$. Around $18 \%$ cases had malignant or premalignant changes. However, frank invasion was seen in $7.25 \%$ (Table 5).

Table 6: Pap smear.

\begin{tabular}{|lll|}
\hline Pap smear & $\begin{array}{l}\text { Total no. of } \\
\text { cases }(\mathbf{n = 5 5})\end{array}$ & Percentage \\
\hline Erosion & 2 & $3.64 \%$ \\
\hline Inflammatory & 42 & $76.36 \%$ \\
\hline Mild dysplasia & 4 & $7.27 \%$ \\
\hline Moderate dysplasia & 1 & $1.82 \%$ \\
\hline Severe dysplasia & 3 & $5.45 \%$ \\
\hline Carcinoma in-situ & 1 & $1.82 \%$ \\
\hline Malignancy & 2 & $3.64 \%$ \\
\hline
\end{tabular}


Majority (76.36\%) of the cases had an inflammatory report on Pap smear (Table 6). Upon correlating Pap smear with histopathology it was seen that an inflammatory smear missed 3 cases of pre-malignancy and malignancy. It was also observed that smears with higher grades of dysplasia correlated well with histopathology (Table 7). The current study showed that the major advantage of colposcopy was to outline the suspicious area in the cervix for histologic diagnosis by directed biopsy. The best correlation was seen with atypical vessels on colposcopy (Table 8).

Table 7: Pap smear of various pre-malignant and malignant cases.

\begin{tabular}{|c|c|c|c|c|c|c|c|}
\hline \multirow{2}{*}{ Pap smear } & \multicolumn{6}{|c|}{ Histopathological findings } & \multirow{2}{*}{ Total } \\
\hline & CIN I & CIN II & CIN III & CIS & Microinvasive & Invasive & \\
\hline Normal & - & - & - & - & - & - & - \\
\hline Inflammatory & 1 & 1 & - & - & - & 1 & 3 \\
\hline Mild dysplasia & 1 & - & - & - & - & - & 1 \\
\hline Moderate dysplasia & - & - & - & - & - & - & - \\
\hline Severe dysplasia & - & - & 1 & 1 & 1 & - & 3 \\
\hline $\mathrm{Ca}$ in situ & - & - & - & 1 & - & - & 1 \\
\hline Malignancy & - & - & - & - & - & 2 & 2 \\
\hline Total & 2 & 1 & 1 & 2 & 1 & 3 & 10 \\
\hline
\end{tabular}

Table 8: Colposcopy findings and its correlation with pre-malignant and malignant lesions.

\begin{tabular}{|llll|}
\hline Colposcopic finding & No. of cases $(\%)$ & $\begin{array}{l}\text { Correlation with pre-malignant and malignant lesions } \\
\text { No. }\end{array}$ & \begin{tabular}{l} 
Percentage \\
\hline Normal
\end{tabular} \\
\hline Acetowhite epithelium & $0(0.00 \%)$ & 0 & $0.00 \%$ \\
\hline Punctation & $16(29.09 \%)$ & 9 & $56.25 \%$ \\
\hline Mosaics & $11(20.00 \%)$ & 4 & $36.36 \%$ \\
\hline Leukoplakia & $6(10.91 \%)$ & 2 & $33.33 \%$ \\
\hline Atypical vessels & $0(0.00 \%)$ & 0 & $0.00 \%$ \\
\hline Erosion & $11(20.00 \%)$ & 9 & $81.82 \%$ \\
\hline Polyps & $25(45.45 \%)$ & 0 & $0.00 \%$ \\
\hline Inflammation & $2(3.64 \%)$ & 0 & $0.00 \%$ \\
\hline Malignancy & $9(16.36 \%)$ & 0 & $0.00 \%$ \\
\hline
\end{tabular}

The sensitivity, specificity, positive predictive value (PPV) and negative predictive value (NPV) of colposcopy in detection of premalignant and malignant cases in this study was found to be $90 \%, 91.1 \%, 69.2 \%$ and $97.6 \%$ respectively (Table 9 ).

Table 9: Significance of colposcopy.

\begin{tabular}{|lll|}
\hline Colposcopy & \multicolumn{2}{|l|}{$\begin{array}{l}\text { Pre-malignancy and malignancy } \\
\text { on histopathology report }\end{array}$} \\
\cline { 2 - 3 } & Present & Absent \\
\hline Positive & 9 & 4 \\
\hline Negative & 1 & 41 \\
\hline
\end{tabular}

The sensitivity, specificity, positive predictive value (PPV) and negative predictive value (NPV) of Pap smear in detection of premalignant and malignant cases in this study was found to be $70 \%, 91.1 \%, 63.6 \%$ and $93.2 \%$ respectively (Table 10).
Table 10: Significance of Pap smear.

\begin{tabular}{|l|l|l|}
\hline Pap smear & \multicolumn{2}{|l|}{$\begin{array}{l}\text { Pre-malignancy and malignancy } \\
\text { on histopathology report }\end{array}$} \\
\hline Present & Absent \\
\hline Positive & 7 & 4 \\
\hline Negative & 3 & 41 \\
\hline
\end{tabular}

Table 11: Correlation of results.

\begin{tabular}{|llll|}
\hline Pap smear & Colposcopy & Histology & Percentage \\
\hline Negative & Negative & Negative & $64.45 \%$ \\
\hline Positive & Negative & Negative & $1.82 \%$ \\
\hline Negative & Positive & Positive & $5.45 \%$ \\
\hline Negative & Positive & Negative & $7.27 \%$ \\
\hline Positive & Positive & Positive & $10.91 \%$ \\
\hline Positive & Positive & Negative & $5.45 \%$ \\
\hline Negative & Negative & Positive & $0.00 \%$ \\
\hline
\end{tabular}


Thus, it was concluded that the accuracy of cytology when compared to colposcopy was $81.82 \%$, the accuracy of colpo-histopathology was $83.6 \%$. While their combined accuracy was $76.36 \%$ (Table 11 ).

\section{DISCUSSION}

This study showed that the cases of pre-malignancy and malignancy were higher in the age group of 31-40 years, which is in accordance with the studies done by Jemal A, et al who showed in their cancer statistics that the distribution of cases is bimodal which peaks at 35-39 years and 60-64 years of age while Algotar K et al in their study showed that the majority of the cases were in the age group of 31-50 years. ${ }^{9,10}$

In this study the incidence of cervical lesions increased with parity (3 or more) and that as parity increased, incidence of the pre-malignant and malignant lesions also increased. Thus, high parity being one of the risk factor for cervical cancer, similar findings were reported in the study done by Algotar K et al. ${ }^{10,11}$ It was seen that though the commonest symptom in the women was leucorrhoea (49\%), 6 out of $10(60 \%)$ women of pre-malignant and malignant disease presented with either post-coital or intermenstrual bleeding, which was in line with the study done by Jemal A et al. ${ }^{9}$

This study also demonstrated that $80 \%$ of the premalignant and malignant lesions were found in the cases with unhealthy cervix which formed $40 \%$ of the total study population. This was consistent with the findings of Arora R et al who suggested that unhealthy cervix was a very common finding in our country due to poor genital hygiene, malnutrition and multiparity. ${ }^{12}$

Arora $\mathrm{R}$ et al conducted their study and reported the incidence of inflammatory Pap smear as $75 \%$ in their study, similar results were seen in this study as well where the incidence of inflammatory smear was $76.36 \% .^{12}$

It was seen that Pap smear missed 3 cases of premalignancy and malignancy in this study which were reported as inflammatory smears. An earlier study by Lawley TB et al, suggested similar findings that cervical smear may have a false negative rate as high as $20 \%$, thus stressing the need for adjunctive investigations. ${ }^{13}$

The colposcopic findings varied, often with more than one finding in the same patient. These ranged from mosaics, acetowhite epithelium, punctation, atypical vessels, erosion, chronic inflammation, polyp and malignancy. Best correlation of colposcopy and premalignant and malignant lesions were seen in cases of atypical blood vessels $(81.8 \%)$. This study data corroborates the findings of Handa PR et al, who demonstrated that the best correlation of malignancy and pre-malignancy was seen with abnormal vessels $(75 \%) .{ }^{14}$
However, there were various findings suggestive of malignancy on colposcopy but which turned out to be only changes of chronic inflammation on histopathology. Hence, colposcopy gave a few false positives.

In this study, 2 cases were positive for pre-malignancy on both smear as well as colposcopy, but were normal on biopsy. These two cases were of prolapse with a decubitus ulcer. Disparity was seen in postmenopausal women as a result of atrophic changes.

Jones HW, in the text book of Telindes operative gynaecology, $9^{\text {th }}$ edition, states that in postmenopausal women, atrophy can cause minor cellular atypia mimicking a LSIL (mild dysplasia) on a pap smear. In such cases, treatment with topical estrogen for 2 months may be helpful before repeating the cytology study. ${ }^{15}$ Baliga $S$ et al, in their study on pitfalls of colposcopy in post-menopausal women concluded that atrophic changes could cause problems at colposcopy and estrogen therapy helps to overcome them. ${ }^{16}$ Massad S et al, in their study quoted the sensitivity of colposcopy as $89 \%$, while that in this study was $90 \% .^{17}$

The sensitivity of a traditional pap smear is $50-60 \%$ and specificity of approximately $90 \%$ according to Lisa Flowers et al which in this study was $70 \%$ and $91.1 \%$ respectively. ${ }^{18}$

The accuracy of the vaginal smear as a screening test quoted in literature by Achenbach RR et al was $70 \% .{ }^{19}$

In a multicentre screening study by Sankaranarayanan $\mathrm{R}$ et al, the sensitivity of cytology varied between different studies. ${ }^{20}$ This indicated the need of improvement in sample preparations, cytological evaluation and clinical judgment are essential to achieve high sensitivity and specificity.

Lawley TB et al, hypothesized that since cervical smears have a high false negative $(20 \%)$ rate, adjunctive investigations may uncover some of these deficiencies. ${ }^{13}$ Ambiye VR et al, on screening 300 patients found that, combined cytology and colposcopy can detect early cases missed by any single method. ${ }^{21}$ They summarized that routine use of these techniques in screening cervical erosion will go a long way in early detection of preinvasive carcinoma of the cervix.

Benedet JL et al, concluded that colposcopy is most accurate in identifying high grade lesions. ${ }^{22}$ They also stated that colposcopic impression correlated closely with the cytology diagnosis and combining the two produces optimum results.

Tamiolakis $\mathrm{D}$ et al, in their study of 58 subjects concluded that an integrated cytology-colposcopy program facilitates the assessment and identification of women harboring cervical pathological conditions, 
similar results were also obtained by Shiela $\mathrm{W}$ et al, Singh V et al, and Saraiya U et al..$^{23-26}$

Arora $\mathrm{R}$ et al, also felt that even repeat Pap smears showing inflammation may fail to detect any abnormality, and CIN may be detected in lot of women by colposcopic biopsy. ${ }^{12}$ Cytology showing an inflammatory smear needs further evaluation by colposcopy. Indian women may not be in a position to come for repeat Pap smear after treatment of infection. Hence, there is an obvious advantage to examine them in the colposcopic clinic before sending them away in the same sitting. Thus, cytology is an accepted method of screening for cervical neoplasia and the value of colposcopy is recognized mainly in the evaluation of patients with abnormal cervical smear. ${ }^{27}$

\section{CONCLUSION}

Given the preponderance of cervical cancer which leads the list of cancers in India and cancer of cervix being a disease continuum, it offers great opportunity to pre-empt and tackle it in the pre-malignant phase thereby preventing invasive cancer.

Pap smear is a primary screening tool for cervical intraepithelial neoplasia and invasive cancer of the cervix. Its use has leads to the successful reduction of deaths from cancer cervix in many parts of the world therefore Pap test should be established as a routine diagnostic tool in gynecological out patient department. Colposcopy is of immense help for directed biopsy of the cervix with accuracy, to avoid many unnecessary biopsies. The simultaneous use of cytological studies and screening colposcopy has been shown to increase the cervical cancer detection. Colposcopy offers an excellent tool in the hands of a gynaecologist to evaluate the uterine cervix and it is not possible to develop this kind of perspective by any other method.

Correlation of Pap smear and colposcopy taking histopathology as the diagnostic tool in this study was good (76.35\%). Combination of cytology and colposcopy helped in successful identification early pre-malignant and malignant lesions, thereby enabling strategies towards betterment of the women.

\section{ACKNOWLEDGMENTS}

Authors would like to thank all the doctors, nurses, staffs, of department of obstetrics and gynecology for their kind support during the study. Authors would like to express their sincere gratitude and respect to all patients who participated in the study.

\section{Funding: No funding sources} Conflict of interest: None declared

Ethical approval: The study was approved by the Institutional Ethics Committee

\section{REFERENCES}

1. Chhabra S. Modes and means of early diagnosis of pre-cancerous lesions of cervix, some glimpses. J Obst Gynae India. 2000;50:32-7.

2. Pandey K, Ajay B. Cancer cervix - need for mass surveillance program specially in rural areas. J Obst Gynae India. 2005;55:436.

3. Parkin DM, Bray F, Ferlay J, Pisani P. Global cancer statistics, 2002 CA. Cancer J Clin. 2005;55:74-108.

4. Parkin DM, Bray F, Chapter 2: The burden of HPV related cancers. Vaccine. 2006;24 (suppl.3):S11-25.

5. Miller AB. Gynecology oncology. Churchill Livingston, London; 1992:543.

6. Jadranka R. Squamous Intra-epithelial lesion. Arch Oncol. 2001;9(3):165-70.

7. Coppleson M, Pixely E, Reid B. "Colposcopy" a scientific and practical approach to cervix and health and disease. Thomas CC, $2^{\text {nd }}$ Edition; 1978.

8. Hudson E. The prevention of cervical cancer: The place of cytological smear test. Clin Obstet Gynaecol. 1985;12:33-51.

9. Ahmedin J, Siegel R, Elizabeth W, Taylor M, Jiaquan X, Carol S. Cancer statistics. Cancer J Clin. 2006;56:106-30.

10. Algotar K, Nalawade A, Sachdev S. Predictive value of colposcopy in cervical cancer screening. Bombay Hospital J. 2004:4603

11. Berek JS. Cervical and vaginal cancer. Berek and Novaks gynecology, $15^{\text {th }}$ Ed. New York, NY: Lippincott Wiliams and Wilkins; 2012:2262-2264.

12. Arora R, Vijaya K, Habeebullah S, Oumachigui A. Colposcopic evaluation of unhealthy cervix. J Obstet Gynaecol India. 2000;50:102-3.

13. Lawley TB, Lee RB, Kapela RR. The significance of moderate and severe inflammation on class I Papanicolaou smear. Obstet Gynecol. 1990;76:997.

14. Handa PR, Dhall GI. Colposcopy as diagnostic aid in cases of suspicious cervix. J Obstet Gynaecol India. 1991;41(6):785-92.

15. Jones HW. Cervical cancer precursors and their management. Telindes operative gynecology. $9^{\text {th }}$ edition; 2015:1354-1360.

16. Jammalamadaka A, Manjula J, Baliga BS. Problems and pitfalls of colposcopy in postmenopausal women. J Obstet Gynecol India. 2007;57:525-9.

17. Massad SL, Collins YC. Strength of correlations between colposcopic impression and biopsy histology. Gynecol Oncol. 2003;89(3):424-8.

18. Flowers LC, McCall MA. Diagnosis and management of cervical intraepithelial neoplasia. Obstet Gynaecol Clinic North Am. 2001;28(4):66784.

19. Achenbach RR, Johnstone RE, Hertig A. The validity of vaginal smear diagnosis in carcinoma insitu of the cervix. Am J Obstet Gynecol. 1951;61:385.

20. Sankaranarayanan R, Thara S, Sharma A, Roy C, Shashtri S, Mahe C, et al. Multicentre study group on cervical cancer early detection in India. Accuracy of 
conventional cytology: results from a multicentre screening study in India. J Med Screen. 2004;11(2):77-84.

21. Ambiye VR, Shroff C, Allahbadia G, Shanbhag AM, Vaidya PR. Cytology, colposcopy and colposcopically directed biopsy in screening of cervical erosion. $\mathbf{J}$ Obstet Gynaecol India. 1989;39:93-6.

22. Benedet JL, Matisic JP, Bertrand MA. An analysis of 84,244 patients from the British Columbia cytologycolposcopy program. Gynaecol Oncol. 2004;92(1):127-34.

23. Tamiolakis D, Kalloniatou M, Lambropoulou M, Kambanieris M, Tsopelas A, Daskalakis G, et al. Contribution of combined colposcopy and cytology in cervical pathology. Arch Gynecol Obstet. 2005;273:39-42.

24. Shiela W, Azhagammai, Kanthamani PN. Histocytocolposcopic evaluation of 30 cases of postmenopausal bleeding. J Obstet Gynaecol India. 1991;41:99-102.
25. Singh V, Das DK, Murthy NS, Luthra UK. Colposcopic observations in precancerous and early cancerous lesions of uterine cervix. J Obstet Gynaecol India. 1989;39:392.

26. Saraiya UB, Lulla M. Role of colposcopically directed target biopsy in the management of early cervical neoplasia. J Obstet Gynaecol India. 1986;36(4):700-7.

27. Bharti B. Role of colposcopy in the evaluation of lower female genital tract in 175 symptomatic women. J Obstet Gynaecol India. 2004;5:4.

Cite this article as: Gupta P, Faruqi M, Chandra S, Shah SS, Kulshrestha R. The correlation between colposcopy, cervical cytology and histopathology in the diagnosis and management of cervical lesions: a cross sectional study. Int J Reprod Contracept Obstet Gynecol 2020;9:2729-35. 